\title{
Psicologia no Contexto da Ditadura Civil-militar e Ressonâncias na Contemporaneidade
}

\author{
Fabíola Figueirêdo da Silva \\ Universidade Federal de São Paulo, SP, Brasil.
}

\begin{abstract}
Resumo: Este trabalho tem por objetivo versar sobre as relações da Psicologia com a sociedade no contexto da ditadura civil-militar, considerando o papel das entidades de Psicologia nesse período. Há algumas considerações sobre as características deste contexto histórico e os seus efeitos na subjetividade dos indivíduos que vivenciaram tal momento. $\mathrm{O}$ artigo propõe também uma reflexão acerca dos desafios da Psicologia no cenário brasileiro contemporâneo. Foi adotado o tipo de pesquisa bibliográfica, e os dados obtidos foram analisados de forma qualitativa, utilizando-se livros e artigos científicos de língua portuguesa. A ditadura nos remete a um período violento e triste na história brasileira, que teve a característica da violação dos direitos humanos, sendo comum as práticas de tortura, prisões ilegais e mortes. Inicialmente, as associações profissionais dos psicólogos priorizavam questões organizativas e técnicas da profissão, evitando entrar em conflito com a ideologia do Estado ditatorial; e é justamente neste período que a profissão foi consolidada, com a atuação destas entidades que tinham por finalidade defender e representar a categoria dos psicólogos. Contudo, tais associações possuíam postura ambígua frente à violência de Estado: não se pronunciavam contra o regime, ao mesmo tempo em que eram coniventes com esse sistema repressivo. Atualmente, em que se reconhece o compromisso da Psicologia com a realidade em que está inserida, a produção de memória sobre este período da história é fundamental para se compreender as relações complexas que existiram durante a ditadura militar, e que repercutem até os dias atuais.
\end{abstract}

Palavras-chave: História da Psicologia, Ditadura, Direitos Humanos. 


\title{
Psychology in the Context of the Military Civil Dictatorship and Resonances in the Contemporaneity
}

\begin{abstract}
The purpose of this paper is to study the relationship between psychology and society in the context of civil-military dictatorship, considering the role of Psychology entities in this period. There are some considerations about the characteristics of this historical context and its effects on the subjectivity of individuals who experienced such a moment. The article also proposes a reflection on the challenges of Psychology in the contemporary Brazilian scenario. A bibliographic research was conducted, and data obtained were qualitatively analyzed, being used scientific books and articles in Portuguese language. The dictatorship refers to a violent and sad period in Brazilian history, which had the characteristic of violations of human rights, being common practices of torture, illegal prisons and deaths. Initially, professional associations of psychologists prioritized organizational and technical issues of the profession, avoiding conflict with the ideology of the dictatorial state; and it was precisely in this period that the profession was consolidated, with the performance of these entities whose purpose was to defend and represent the category of psychologists. However, such associations had an ambiguous stance against state violence: they did not speak out against the regime, being conniving at the same time with this repressive system. Nowadays, recognizing the commitment of Psychology to the reality in which it is inserted, and the production of memory about this period of history are fundamental to understand the complex relationships that existed during the military dictatorship, which have repercussions until the present day.
\end{abstract}

Keywords: History of Psychology, Dictatorship, Human Rights.

\section{Psicología en el Contexto de la Dictadura Civil Militar y Resonancias en la Contemporaneidad}

Resumen: Este trabajo tiene por objetivo versar sobre las relaciones de la Psicología con la sociedad en el contexto de la dictadura civil-militar, considerando el papel de las entidades de Psicología en ese período. Hay algunas consideraciones sobre las características de este contexto histórico y sus efectos en la subjetividad de los individuos que han vivido tal momento. El artículo propone también una reflexión acerca de los desafíos de la Psicología en el escenario brasileño contemporáneo. Se adoptó el tipo de investigación bibliográfica, y los datos obtenidos fueron analizados de forma cualitativa; y se utilizaron libros y artículos científicos de lengua portuguesa. La dictadura nos remite a un período violento y triste en la historia brasileña, que tuvo como característica la violación de los derechos humanos, siendo comunes las prácticas de tortura, prisiones ilegales y muertes. Inicialmente, las asociaciones profesionales de los psicólogos priorizaban cuestiones organizativas y técnicas de la profesión, evitando entrar en conflicto con la ideología del Estado dictatorial; y es justamente en este período que la profesión fue consolidada, con la actuación de estas entidades que tenían por finalidad defender y representar la categoría de los psicólogos. Sin embargo, tales asociaciones poseían postura ambigua frente a la violencia de Estado: no se pronunciaban contra el régimen, al mismo tiempo siendo conniventes con ese sistema represivo. Actualmente, cuando se reconoce el compromiso de la Psicología con la realidad en la que está incluida, la producción de memoria sobre este período de la historia es fundamental para comprender las relaciones complejas que existieron durante la dictadura militar, y que repercuten hasta los días actuales.

Palabras claves: Historia de la Psicología, Dictadura, Derechos Humanos. 


\section{Introdução}

\section{O compromisso da Psicologia com o resgate de sua própria história}

Um dos sentidos do trabalho do psicólogo consiste em promover a saúde e a qualidade de vida de indivíduos e de coletividades, o que está relacionado com a dimensão ética de sua profissão (Conselho Federal de Psicologia, 2005). Em sua atuação, faz-se importante também conhecer e resgatar a história do próprio contexto social, para que se possa analisar, de forma crítica, os múltiplos determinantes que compõem a realidade que vivencia.

Tais pressupostos estão em conformidade com o Código de Ética Profissional do Psicólogo (CFP, 2005) e podem contribuir para o desenvolvimento da Psicologia, tendo em vista que refletem um interesse na vida e nos valores humanos, bem como no enriquecimento da construção de sentidos de seu saber e conjunto de práticas.

O trabalho de Antunes (2012) tece considerações sobre a história da Psicologia brasileira, abarcando suas características e as produções teóricas e práticas em cada período de tempo. Em sua análise, considera as construções históricas, sociais, poíticas, econômicas para citar alguns aspectos - que influenciaram os modos da Psicologia em produzir conhecimentos, de compreender o homem, atingindo assim suas próprias práticas.

Inicialmente, a Psicologia se preocupou com os discursos sobre a subjetividade presentes em diversas áreas do saber, especialmente atrelada à filosofia, medicina e educação. Ao longo da história de sua consolidação no Brasil, alguns cursos e laboratórios foram criados de forma a se debater as questões psicológicas. No avanço do reconhecimento desta área, foram marcos consideráveis a regulamentação da profissão pela Lei $\mathrm{n}^{\circ} 4.119$, em 27 de agosto de 1962, e a criação de dispositivos formais mediante a Lei $\mathrm{n}^{\circ} 5.766$, como os Conselhos Federal e Regionais de Psicologia, em 20 de dezembro de 1971 (Pereira, \& Pereira Neto, 2003).

Cabe salientar que pesquisar em Psicologia e resgatar sua própria história envolve aspectos éticos, estéticos e políticos. Deve-se reconhecer a complexidade do fenômeno que está sendo estudado, bem como os valores e a atuação do pesquisador neste processo de pesquisa. Trata-se de um processo de criação e intervenção na própria realidade, posto que implica em relações entre sujeitos e a sociedade, que são mutuamente constitutivos. Ainda, considera-se que, por ser uma prática social, o processo de pesquisa é vinculado às condições históricas do contexto em que se vive, visando sua compreensão, entendimento e proposta de soluções para a transformação da realidade (Zanella, \& Sais, 2008).

Com base nisso, para a compreensão dos primórdios da Psicologia brasileira, é fundamental o estudo das intensas mudanças no cenário político-social que repercutiram sobre a sua existência. Desta forma, estudar as histórias da Psicologia durante o período da ditadura militar envolve a sua apreensão enquanto criação humana, e como tal, relacionada com este período sócio-histórico (Cambaúva, Silva, \& Ferreira, 1998).

Este trabalho visa uma reflexão sobre as relações entre a Psicologia e a ditadura civil-militar, considerando o papel das entidades de Psicologia nesse contexto. Este estudo tece algumas considerações sobre as características deste período e os seus efeitos na subjetividade dos indivíduos que vivenciaram tal momento histórico. Por fim, tem-se uma reflexão acerca dos desafios da Psicologia no cenário brasileiro contemporâneo.

\section{Método}

Para a realização deste trabalho, foi adotado o tipo de pesquisa bibliográfica, que consiste no "exame, levantamento e análise do material existente sobre determinado assunto". (Di Domenico, \& Cassetari, 2010, p. 69). Os materiais utilizados foram livros e artigos científicos, principalmente da área da Psicologia, datados de 1985 até o presente ano. Como critério de inclusão, foram levantados textos que se relacionassem com a temática do estudo, que fossem de língua portuguesa, e excluídos materiais que não tivessem relação com o objetivo da pesquisa. Os descritores utilizados na seleção de artigos foram: História da Psicologia; Ditadura; Direitos Humanos.

\section{Características da ditadura civil-militar brasileira}

A ditadura civil-militar brasileira, que compreende o período de 1964 a 1985, nos remete a um momento triste e violento na nossa própria história, caracterizado pela violação dos direitos humanos, sendo comum as práticas de tortura, prisões ilegais e mortes. Quando os militares tomaram o poder, com a ideologia de segurança nacional, desprezaram o sistema político instituído e as suas instituições (como Congresso, Judiciário, dentre outros), criando suas 
próprias regras de funcionamento (Scarparo, Torres \& Ecker, 2014). Para justificar as suas ações, criaram os Atos Institucionais, compreendidos como um conjunto de normas que concediam plenos poderes aos militares, além da criação de vários dispositivos e órgãos secretos de informações e de segurança. O país atravessava um período turbulento, caracterizado por manifestações da população contrários ao este regime ditatorial, e ainda agravado pela alta concentração de renda, inflação e dívida externa (Chiavenato, 1994).

Houve uma verdadeira agressão ao público, de forma geral. Por exemplo, ocorreu diminuição de verbas na saúde; agressão à educação, pelo desprezo ao ensino básico, tendo como consequência milhões de crianças sem estudos; ataque à Universidade, considerando a invasão de seus estabelecimentos, com a apreensão de documentos e livros, demissão de reitores, professores e funcionários e expulsão de estudantes que não se alinhavam aos valores da ditadura; agressão à cultura, com a proibição e censura de inúmeras peças, filmes e músicas; agressão ao trabalho, pela perda de direito do trabalhador, que sequer podiam se reivindicar por seus direitos, e se rebelar em greves, além dos baixos salários fornecidos, para qual a capacidade de consumo era pouca. O país também experimentou uma brutal censura à imprensa: qualquer ação que pudesse ofender o governo não poderia ser veiculada (Chiavenato, 1994).

Nesse momento histórico, tem-se relatos e provas de cidadãos que foram cruelmente torturados e mortos, sendo que, em muitos casos, houve contradições em documentos oficiais falseados ou inexistentes. Ocorriam detenções sem mandato judicial, com desrespeito às leis que garantem direitos aos cidadãos. Eram comuns torturas de várias formas, sessões de eletrochoque, queimaduras, afogamentos, cadeiras e camas eletrificadas, utilização de insetos e animais perigosos durante interrogações, utilização de produtos químicos, cadáveres dos opositores políticos eram largados em terrenos baldios ou sepultados anonimamente. Mendigos nas ruas e cidadãos comuns eram utilizados como cobaias, e assim torturados em aulas de militares nos quartéis. Inclusive, a tortura foi incluída como disciplina nos currículos de formação de militares. Nem mesmo crianças, mulheres, gestantes e idosos eram poupados (Arantes, 2012; Arquidiocese, 1985; Chiavenato, 1994).

E ainda houve indivíduos que foram torturados com a assistência de agentes da saúde, o que tornam ainda mais graves tais abusos (Martín, 2005). Assim, a tortura foi apoiada e respaldada por muitos profissionais da saúde, como psicólogos, psiquiatras, médicos, e de outras áreas do conhecimento, que por meio de seus saberes e práticas fortaleceram ações de violência e de exclusão. Poderiam argumentar que estavam cumprindo ordens, no entanto, tais práticas apoiaram e fortaleceram os terrorismos do Estado, numa dessensibilização frente à violência (Coimbra, 2001). Tais atos podem ser caracterizados pela negação do próprio desenvolvimento humano (Santos, 1994).

Como consequência, as sequelas psicológicas podem afetar vários aspectos da existência humana: destruição da pessoa e de seus valores, desorganização da relação que o indivíduo tem consigo mesmo e com a sociedade em que vive, havendo a possibilidade de se ter uma conduta que está em maior ou menor consonância com os valores cruéis da ditadura. Embora não haja um quadro sintomatológico único, as sequelas psicológicas de quem vivenciou tais situações podem ser graves e permanentes, considerando a alta porcentagem de suicídios, os problemas identitários, a angústia crônica, os lutos não elaborados, alterações de hábitos alimentares, sexuais dentre outros aspectos, ocorrência de sentimento de culpa e vergonha, de perseguição e de dano, isolamento, dificuldades relacionais e de inserção laboral; apenas para citar algumas consequências. Para tais pessoas que sofreram esses horrores, foram negados o direito à vida e o de realizar os seus projetos pessoais (Martín, 2005).

Outras mudanças estruturais ocorreram, por exemplo, na educação, como a ênfase no ensino tecnicista, conforme a lógica de interesses político-econômicos; no controle da mídia e fortalecimento de instituições de segurança pública (Scarparo et al., 2014). O cenário econômico e atual é de fato, herança e consequência do período militar. Considerando as principais mudanças que ocorreram no período da ditadura militar e que deixaram heranças, marcas, resquícios, cabe o estudo dos efeitos deste período nos processos subjetivos da população brasileira atualmente.

Por se tratar de um tema complexo, várias produções artísticas e projetos políticos foram criados, e que visam a um esclarecimento acerca deste período. Nesse sentido, alguns grupos e instituições tem se esforçado em resgatar essas histórias que foram ocultadas, de forma a denunciar as diferentes violações dos direitos humanos, tanto as do passado, quanto as existentes atualmente; e há também, por parte do Estado, alguns mecanismos de reparação. 


\section{Psicologia no contexto da ditadura civil-militar}

O período da ditadura civil-militar, sem dúvida, marcou a história da formação da Psicologia. Inclusive, foi nesse período que aconteceu a criação das entidades regulamentadoras do exercício profissional do psicólogo, para defender e organizar a categoria. Foi quando houve um crescimento considerável do número de profissionais que se formaram nesta área, devido à criação dos cursos universitários particulares, e do aumento da demanda da população que precisava de serviços psicológicos (Pereira \& Neto, 2003).

O trabalho de Hur (2012) detalha com maestria a criação da profissão e as principais entidades de cunho acadêmico - científico que se organizaram e realizaram intensos debates e articulações políticas. A regulamentação da profissão pela Lei no 4.119 de 27 de agosto de 1962 ocorreu a partir da atuação de entidades como a Sociedade de Psicologia de São Paulo (SPSP) e a Associação Brasileira dos Psicólogos (ABP). Antes da criação dos conselhos de Psicologia, foi necessária a autorização do Estado, que recomendou a organização de sindicato para obter um reconhecimento legal. As associações supracitadas fundaram então a Associação Profissional dos Psicólogos do Estado de São Paulo (APPESP), que foi o projeto do sindicato.

Numa retrospectiva histórica, em 20 de dezembro de 1971, foi aprovada a Lei ${ }^{\circ} 5.766$, sobre a criação dos Conselhos Profissionais de Psicologia e do Conselho Federal de Psicologia. Em 1973 foi criado oficialmente o Sindicato dos Psicólogos no Estado de São Paulo (Spesp) e foi instalado o Conselho Federal de Psicologia. Apenas em 1974 é que foram criados os Conselhos Regionais de Psicologia (Hur, 2007).

De forma geral, estas instituições citadas tiveram uma atuação corporativista na década de 1970, na qual a ênfase de discussão era o campo profissional, e não no campo político. Desta forma, as reivindicações dos psicólogos discutidas em reunião centravam-se em temas operacionais, como ética, fiscalização, testes psicotécnicos, piso salarial, dentre outros (Hur, 2012).

As entidades temiam que um questionamento frente à sociedade pudesse trazer prejuízos para a categoria, num momento em que estavam focados na defesa da profissão (Hur, 2012). De certa forma, evitava-se questionar as políticas do Estado ditatorial, denotando assim uma ausência de crítica para com a violência, a repressão e a perda de direitos humanos, característicos deste momento histórico. Havia, indi- retamente, um posicionamento político de cumplicidade, evidenciado por homenagens feitas a presidentes e ministros que tinham aliança com o regime militar, e considerando que as instituições não se manifestavam publicamente contra o Estado (Hur, 2012).

Por outro lado, consideramos que tal posicionamento de omissão política diante da ditadura civil-militar até favoreceu a expansão da profissão, tendo em vista que as práticas em Psicologia foram consideradas pouco ameaçadoras. Ao privilegiar as questões técnicas da profissão e íntimas e particulares de cada paciente, as questões sociais e políticas ficaram em segundo plano, ou seja, camufladas (Coimbra, 1995). O espaço psicoterapêutico tornava-se atraente, tendo em vista que a palavra de ordem, na sociedade, era o silêncio (Langenback, 1988 citado por Pereira, \& Pereira Neto, 2003). As normas disciplinares psicológicas também puderam ser utilizadas a favor do Estado, em que se patologizava o opositor político. Utilizou-se a falácia de que "os culpados são os indivíduos anormais, de psiquismo patológico, e não o Estado e o regime que os criou e sustentou" (Coimbra, 2001, p. 14).

Assim, de início, a Psicologia brasileira foi orientada predominantemente pelo modelo biológico, numa lógica em que o homem era responsável pelo seu próprio sofrimento, e que tinha que se ajustar à normalização social. Conforme já explicitado, o espaço da clínica foi enfatizado e ganhou status. Deste modo, como o paciente era tratado no consultório particular, preocupado com suas próprias questões emocionais, as reflexões coletivas eram deixadas de lado. Consequentemente, a relação do homem com a sociedade não era articulada claramente (Cambaúva et al., 1998).

Portanto, as práticas psicológicas da época buscavam uma suposta neutralidade, afastada de reflexões sobre os efeitos políticos de suas práticas. Tinham uma função normalizadora, por meio da qual buscavam adaptar os indivíduos a uma sociedade desajustada e opressora, e uma postura ambígua frente à violência de Estado: não se pronunciava contra o regime, mas, ao mesmo tempo, era conivente com esse sistema repressivo (Scarparo et al., 2014).

Na década de 1980 já se percebe uma ruptura com tais ideologias, havendo assim, uma determinada abertura política, por meio de um questionamento da realidade social e ao próprio caráter normatizador das entidades de Psicologia, que participaram de forma mais clara em movimentos como o direito ao voto direto e o fim da ditadura militar (Hur, 2009). 
As temáticas tratadas pelos psicólogos voltavam-se a questões relacionadas à formação profissional e às políticas públicas, sendo questões emergentes na sociedade. Os Conselhos e Sindicatos de Psicologia passam a sustentar um posicionamento político claro pela democratização do país e contra as opressões. Nas décadas seguintes, segue-se o mesmo mote, com uma postura crítica da realidade, que é difundida e discutida na realização de vários eventos na área, como os Congressos Nacionais de Psicologia (Hur, 2012). As entidades regulamentadoras do exercício do psicólogo tiveram uma importante função ao discutir qual é o compromisso social da Psicologia.

Assim, compreende-se que, no período da distensão política da ditadura civil-militar, é que ressurgiram movimentos sociais em prol da luta pelos direitos humanos, por meio dos quais se buscava melhores condições de vida, em todas as esferas, além de esforços para a democratização da sociedade. Desta forma, a partir da emergência desses movimentos que questionavam as lógicas de poder instaladas, as mudanças efetivamente surgiram a partir de mudança de paradigmas, e pelos esforços por uma sociedade ética e transparente (Coimbra, Lobo, \& Nascimento, 2008).

Há de se ressaltar que as lutas pela democratização empreendidas pelos movimentos sociais a partir da segunda metade da década de 1970 e pelas entidades de Psicologia no início da década de 1980 tratam de "uma luta de todos, e de todas as sociedades [...] uma luta geral, coletiva, por uma nova concepção de mundo, de homem e de humanidade: por uma sociedade sem torturas" (Coimbra, 2001, p. 19). Portanto, consideramos que conhecer o passado é fundamental para que os acontecimentos esvaziados de valores humanos não sejam repetidos pela sociedade e pelo Estado. Este olhar é fundamental para que os fatos não sejam esquecidos, também por consideração e memória pelos que lutaram por um país mais justo.

\section{Considerações finais}

\section{Reflexões acerca dos desafios da Psicologia contemporânea}

Considera-se que se fazem necessários mais estudos acerca da história da Psicologia e de suas relações com os múltiplos determinantes sociopolíticos que a influencia, para que possamos compreender quais conhecimentos estamos produzindo, a finalidade e as repercussões disso na própria sociedade. Nas palavras de (Antunes, 2012):

no caso da Psicologia no Brasil, faz-se necessário compreendê-la como construção histórica e social, síntese de múltiplas determinações, orientada por determinadas concepções de homem e de sociedade e comprometida com posições de classe e, portanto, contraditória, sendo que o embate entre esses elementos que se opõem produz movimento e possibilita superação.

Ainda há poucos estudos sobre a problematização da prática psicológica em tempos de ditadura civil-militar. Estudar este passado é entender que os saberes estão em contínua transformação e que não são conhecimentos neutros, considerando que estão relacionados com as relações de poder existentes. Desta forma, "olhar para a ditadura é entender como foi engendrado o presente, evitando que a categoria profissional venha a ser utilizada - por determinados grupos ou saberes/poderes - na produção de processos de captura e dominação subjetiva" (Scarparo et al., 2014, p. 71).

Ao voltar-se neste período da história brasileira, uma das indagações que podem ser feitas é com relação aos abusos cometidos, e eis que surge um sentimento de incompreensão à primeira vista: Como entender todas as torturas, as prisões, desaparecimentos e mortes? Como entender tais atrocidades cometidas contra as pessoas que viveram naquele contexto histórico-social? Quais as repercussões e marcas deste período na atualidade, e como isso tem influenciado os modos de relação entre o indivíduo, sociedade e Estado?

O Código de Ética Profissional do Psicólogo (CFP, 2005) é bem claro no tocante aos direitos humanos. O psicólogo não deve ser conivente com práticas que caracterizem violência, opressão, negligência, discriminação e práticas desse tipo, nem mesmo com o uso de conhecimentos e práticas psicológicas para tal finalidade. Há pesquisas na área psicológica que indicam a violência manifestada sob diversas formas e que atinge vários setores da sociedade. Enfim, o psicólogo não deve consentir com qualquer demonstração de violação de direitos humanos e faltas éticas, aliás, deve contribuir para eliminar estas formas opressivas.

Ignorar tais palavras prescritas no código implica no desrespeito a princípios e direitos inalienáveis ao ser humano. As declarações, códigos e resoluções são 
legitimados quando postos em prática. Por isso que se faz importante a reflexão acerca das questões da sociedade que afetam a população, que interferem nos modos de vida, percebendo as consequências disso, para que se possa analisar e propor alternativas de mudanças. E considera-se que, desde o período de reabertura política, os Conselhos de Psicologia vêm adotando um papel importante neste processo de democratização da sociedade.

Os obstáculos podem ser superados se a Psicologia focalizar a sua atenção aos avanços coletivos na direção da implementação do processo democrático, com a questão da igualdade e aceitação das diferenças que o tema abrange. Lembrando-se que mudanças podem ser propostas a partir da demanda pela cidadania. O que reanima é saber da potencialidade existente na categoria dos psicólogos para a transformação da realidade (Carrara,1996).

Nas palavras de Scarparo et al. (2014, p. 71),

refletir sobre as práticas psicológicas em época de ditadura possibilita colocarmos nossas produções contemporânea em análise. Neste sentido, apontamos algumas questões que emergem: que lugar a psicologia tem ocupado nessa sociedade desigual? Para que e para quem nossos conhecimentos têm servido? Que violações de direito estamos praticando, mesmo sob a pretensa justificativa de neutralidade científica?

Nota-se que a Psicologia vem conquistando maior visibilidade, sendo inserida e legitimada em diversos contextos sociais. Compreende-se que atualmente há uma pluralidade de teorias e técnicas psicológicas em seu escopo. Porém, mais do que o conhecimento de disciplinas técnicas e científicas, o psicólogo deve ter uma atuação comprometida com a realidade e com as necessidades da população.

Reafirma-se, novamente, que a Psicologia precisa estar articulada com o projeto coletivo, de forma a apreender os diversos significados compartilhados na relação entre os indivíduos. Isto faz parte de sua tentativa de compreensão dos fenômenos humanos. Nesse sentido, a formação profissional do psicólogo envolve o compromisso individual, bem como o compromisso coletivo, tendo em vista que tornar-se um profissional em Psicologia envolve assumir o seu papel de cidadão (Santos, 1994). Portanto, urge pensar a Psicologia em seu projeto social e histórico, em sua devida arti- culação com a realidade que vivencia, considerando as relações de poder existentes de sua realidade e o impacto desses fenômenos em seu cenário de atuação. O resgate da própria história permite a apropriação do senso crítico, culminando no compromisso social do indivíduo desde o momento de sua formação (Cambaúva et al., 1998). Deste modo, a Psicologia deve privilegiar um processo formativo contextualizado e formalizar a participação como estratégia de trabalho ou, em outras palavras, levar em consideração as teorias existentes, refleti-las e articulá-las com a realidade social vivida (Carrara,1996).

Nesse sentido, as reminiscências e os relatos das pessoas que passaram por esse período turbulento são imprescindíveis para que se propicie o resgate de narrativas e histórias que, além de serem únicas, são coletivas, por representarem este período turbulento, e que consequentemente, fazem parte da história brasileira.

Por isso a produção de memória deste período é essencial, para o entendimento de questões sociais que enfrentamos hoje. Só pode se pensar acerca da realidade e dos direitos humanos se olharmos e compreendermos as relações complexas que existiram durante o passado, percebermos as lógicas que operaram e que ainda são produzidas atualmente. Quando se conhece os fatos do passado, por meio das narrativas de quem vivenciou tais acontecimentos, abrem-se possibilidades de se compreender as repercussões disto que acontece no presente, e também, de prevenir tais experiências no futuro (CFP, 2012). São histórias que, embora silenciadas por décadas, não foram esquecidas. O problema recai não somente sobre as vítimas, mas por toda a sociedade que luta por uma sociedade mais digna e democrática (CFP, 2012).

É neste cenário que nos encontramos hoje: entre sombras do passado e reminiscências que repercutem no presente, silêncio, esquecimentos e repetições; omissão e conivência; repressão e resistência, dores do passado que persistem, traumas... É preciso falar sobre tais questões. Há um passado sombrio e obscuro querendo ser enterrado à força, como se, ao simples virar das páginas do tempo, os acontecimentos desaparecessem, fossem apagados com a névoa do suposto esquecimento.

Se faz necessária a tomada de medidas corajosas que viabilizem a consolidação de um país mais justo e democrático e, também, aprender com as lições do passado recente pode fortalecer ainda mais a convicção pela defesa dos direitos humanos, pela defesa da 
ética, pela defesa da cidadania (Arquidiocese, 1985). Além disso, as pesquisas em Psicologia são de suma importância para o avanço da área e para a compreensão dos fenômenos psicológicos, de forma que os conhecimentos sejam utilizados para o bem comum.

Que a Psicologia não se esqueça de suas memórias e que se fortaleça ainda mais como ciência e profissão, de forma a contribuir para a melhoria de diversos setores da sociedade; que possa sempre refletir acerca de sua realidade, resgatando, também sua história, de forma a participar de mudanças que beneficiem toda a população; que, além de estudar a existência humana com sensibilidade e rigor, possa contribuir em sua dignidade, respeito e valorização.

\section{Referências}

Antunes, M. A. M. (2012). A Psicologia no Brasil: um ensaio sobre suas contradições. Psicologia: Ciência e Profissão, 32(spe), 44-65. https://doi.org/10.1590/S1414-98932012000500005

Arantes, M. A. A. C. (2012). Em nome da memória. Psicologia: Ciência e Profissão, 32(spe), 310-317. https://doi.org/10.1590/S1414-98932012000500022

Arquidiocese de São Paulo. (1985). Brasil: Nunca mais (20a ed.). Petrópolis, RJ: Vozes.

Cambaúva, L. G., Silva, L. C., \& Ferreira, W. (1998). Reflexões sobre o estudo da história da Psicologia. Estudos de Psicologia (Natal), 3(2), 207-227. https:// doi.org/10.1590/S1413-294X1998000200003

Carrara, K. (1996). Psicologia e a construção da cidadania. Psicologia: Ciência e Profissão, 16(1), 12-17. https://doi.org/10.1590/S1414-98931996000100003

Chiavenato, J. J. (1994). O golpe de 64 e a ditadura militar (8s ed.). São Paulo, SP: Moderna.

Coimbra, C. M. B. (1995). Guardiões da ordem: uma viagem pelas práticas psi no Brasil do 'milagre'. Rio de Janeiro, RJ: Oficina do Autor.

Coimbra, C. M. B. (2001). Tortura ontem e hoje: resgatando uma certa história. Psicologia em Estudo, 6(2), 11-19. https://doi.org/10.1590/S1413-73722001000200003

Coimbra, C. M. B.; Lobo, L. F., \& Nascimento, M. L. (2008). Por uma invenção ética para os Direitos Humanos. Psicologia Clínica, 20(2), 89-102. https://doi.org/10.1590/S0103-56652008000200007

Conselho Federal de Psicologia - CFP. (2005). Código de Ética Profissional do Psicólogo. Recuperado de http://site. cfp.org.br/wp-content/uploads/2012/07/codigo-de-etica-psicologia.pdf.

Conselho Federal de Psicologia - CFP. (2012). Psicologia e o direito à memória e à verdade (Cadernos temáticos CRP SP, vol. 13). São Paulo, SP: o autor Recuperado de http://www.crpsp.org.br/portal/comunicacao/cadernos_ tematicos/13/frames/caderno_13.pdf.

Di Domenico, V. G. \& Cassetari, L. (2010). Métodos e técnicas de pesquisa em Psicologia: uma introdução (4a ed.). São Paul, SP: Moderna.

Hur, D. U. (2007). A Psicologia e suas entidades de classe: histórias sobre sua fundação e algumas práticas no Estado de São Paulo nos anos 70. Psicologia Política, 13(1). Recuperado de http://www.fafich.ufmg.br/ psicopol/seer/ ojs/viewarticle.php?id=17\&layout=html

Hur, D. U. (2009). O surgimento da esquerda nas entidades profissionais dos psicólogos de São Paulo, CRP-06 e SPESP, no período da abertura política brasileira. Mnemosine, 5(1), 126-145. Recuperado de http://www.mnemosine.com.br/ojs/index.php/mnemosine/article/view/167/pdf_152

Hur, D. U. (2012). Políticas da psicologia: histórias e práticas das associações profissionais (CRP e SPESP) de São Paulo, entre a ditadura e a redemocratização do país. Psicologia USP, 23(1), 69-90. https://doi.org/10.1590/ S0103-65642012000100004

Martín, A. G. (2005). As seqüelas psicológicas da tortura. Psicologia: Ciência e Profissão, 25(3), 434-449. https://doi.org/10.1590/S1414-98932005000300008

Pereira, F. M., \& Pereira Neto, A. (2003). O psicólogo no Brasil: notas sobre seu processo de profissionalização. Psicologia em Estudo, 8(2), 19-27. https://doi.org/10.1590/S1413-73722003000200003 
Scarparo, H. B. K., Torres, S., \& Ecker, D. D. (2014). Psicologia e ditadura civil-militar: reflexões sobre práticas psicológicas frente às violências de estado. Revista EPOS, 5(1), 57-78. Recuperado de http://pepsic.bvsalud.org/scielo. php?script=sci_arttext\&pid=S2178-700X2014000100004

Santos, M. F. S. (1994). Formar psicólogos para quê?. Psicologia: Ciência e Profissão, 14(1-3), 40-41. https://doi. org/10.1590/S1414-98931994000100008

Zanella, A. V., \& Sais, A. P. (2008). Reflexões sobre o pesquisar em psicologia como processo de criação ético, estético e político. Análise Psicológica, 26(4), 679-687. Recuperado de http://www.scielo.mec.pt/scielo.php?script=sci_ arttext\&pid=S0870-82312008000400012\&lng=pt\&tlng=pt

\section{Fabíola Figueirêdo da Silva}

Psicóloga, graduada em Psicologia pela Universidade Braz Cubas, São Paulo - SP. Brasil. Psicóloga residente em Aleitamento Materno e Banco de Leite Humano pela Universidade Federal de São Paulo, São Paulo - SP. Brasil.

E-mail: fabiolafigueiredos@gmail.com

Endereço para envio de correspondência:

Unifesp - Universidade Federal de São Paulo

Rua Botucatu, 740 - Vila Clementino. CEP: 04023-062.

São Paulo - SP. Brasil.

Recebido 28/06/2017

Reformulação 07/10/2017

Aprovado 09/10/2017

Received $06 / 28 / 2017$

Reformulated 10/07/2017

Approved 10/09/2017

Recebido 28/06/2017

Reformulado 07/10/2017

Aceptado 09/10/2017

Como citar: Silva, F. F. (2017). Psicologia no contexto da ditadura civil-militar e ressonâncias na contemporaneidade. Psicologia: Ciência e Profissão, 37(n. spe), 82-90. https://doi.org/10.1590/1982-3703060002017

How to cite: Silva, F. F. (2017). Psychology in the context of the military civil dictatorship and resonances in the contemporaneity. Psicologia: Ciência e Profissão, 37(n. spe), 82-90. https://doi.org/10.1590/1982-3703060002017

Cómo citar: Silva, F. F. (2017). Psicología en el contexto de la dictadura civil militar y resonancias en la contemporaneidad. Psicologia: Ciência e Profissão, 37(n. spe), 82-90. https://doi.org/10.1590/1982-3703060002017 